\title{
Architecture and Data Management Challenges in GEOSS and IEOS
}

\author{
Kathleen S. Fontaine \\ NASA Goddard Space Flight Center \\ Code 610.2 \\ Greenbelt, MD 20771 \\ 301-614-5582 \\ kathy.fontaine@nasa.gov
}

\begin{abstract}
The international Group on Earth Observations (GEO) was initiated in 2003 to engage all the nations of the Earth in building a coordinated, comprehensive, and sustained Earth observation capability, known as the Global Earth Observation System of Systems (GEOSS). The GEO website describes GEOSS this way: "GEOSS will build on and add value to existing Earth-observation systems by coordinating their efforts, addressing critical gaps, supporting their interoperability, sharing information, reaching a common understanding of user requirements, and improving delivery of information to users." Each member nation has responded to GEO by establishing some sort of coordinating body; within the United States, that is the United States Group on Earth Observations (USGEO). This paper will describe the establishment of GEO and USGEO, will provide an overview of the activities and challenges in the area of architecture and data management, and will highlight some of the major efforts underway within USGEO today. ${ }^{12}$
\end{abstract}

\section{TABLE OF CONTENTS}

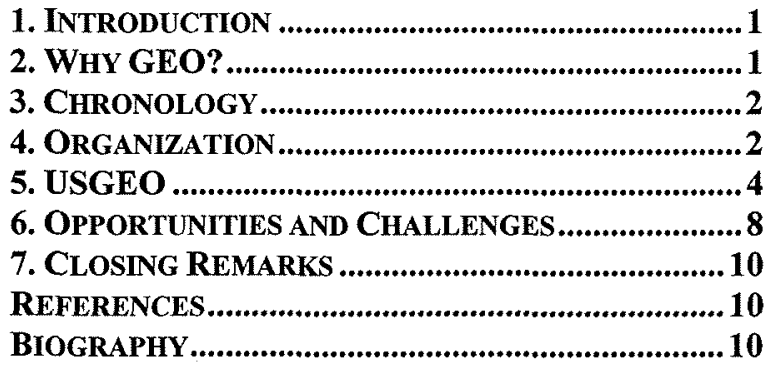

\section{INTRODUCTION}

The international Group on Earth Observations (GEO) was initiated in 2003 to engage all the nations of the Earth in building a coordinated, comprehensive, and sustained Earth observation capability. Key to that capability, and perhaps the greatest challenge, is the realization of a Global Earth Observation System of Systems, or GEOSS. The GEOSS 10-Year Implementation Plan [1], and associated Reference Document [2], has identified nine Societal Benefit Areas on which member agencies and participating organizations can

\footnotetext{
1 U.S. Government work not protected by U.S. copyright.

2 IEEEAC paper \# 1649, Version 3, Updated December 7, 2006
}

focus relevant assets - anything from actual sensors and data sets to processing expertise to user requirements. GEO members and organizations strive to make GEOSS a reality by pooling their collective expertise to address critical issues either within one or more of those nine areas, across all nine at once, or across some combination.

\section{WHY GEO?}

Why would the nations of the earth need to put together a comprehensive, coordinated, sustained effort to address various aspects of global change? More and more, citizens require their governments to make evidence-based policy decisions about the environment, including better predictions of natural disasters, epidemics, the impact of energy choices, or variations in the climate. While neither GEO nor GEOSS will directly take the required comprehensive, systematic Earth system measurements or produce research-quality data products, GEOSS can form the foundation for sound decision-making at the global, regional, and local levels. GEOSS is envisioned as an integrated, international system using remote sensing and in situ systems, to meet societal needs, realizing that no one organization or country can provide comprehensive capacity alone. To highlight just a few social, economic, and science concerns,

- In 1992, the United Nations (UN) estimated that more than half of the world's population lives within $60 \mathrm{~km}$ of a shoreline. According to the UN Association in Canada, seven out of ten people live within $80 \mathrm{~km}$ of the coastline; almost half of the world's cities with a population of over one million are located around coastal areas and river mouths; [3]

- 160 countries have more than one quarter of their population in areas of high mortality risk from one or more hazards; [4]

- Statistics compiled from insurance companies from 1950-1999 show that major natural catastrophes across the globe caused economic losses of $\$ 960$ billion. However, over the same period, loss of life in countries with good observation systems for warning and preparedness has fallen. [5] 
It becomes increasingly clear, as one pages through quotes such as these, that a coordinated, multi-national effort could form the basis for sustainable development. With these and many other statistics and issues in mind, the concept of GEO began to take shape.

\section{Chronology}

The Group on Earth Observations took form over four summit meetings. At the World Summit on Sustainable Development, Johannesburg, in 2002, delegates highlighted the urgent need for coordinated observations relating to the state of the Earth. A meeting of the Heads of State of the Group of 8 Industrialized Countries Summit in June 2003 in Evian, France, affirmed the importance of Earth Observation as a priority activity.

The First Earth Observation Summit was convened in Washington, D.C., in July 2003, and adopted a Declaration establishing the ad hoc intergovernmental Group on Earth Observations (ad hoc GEO) to draft a 10-Year Implementation Plan.

The Second Earth Observation Summit in Tokyo, Japan, in April 2004 adopted a Framework Document defining the scope and intent of a Global Earth Observation System of Systems. This framework document, along with the draft 10-Year implementation plan, served as the source material for all subsequent work plans and tasks.

The Third Earth Observation Summit, held in Brussels in February 2005, endorsed the GEOSS 10-Year Implementation Plan and established the intergovernmental Group on Earth Observations to carry it out. Heads of State further supported GEOSS in the G-8 Gleneagles Plan of Action released in July $2005 .^{3}$

\section{Organization}

Because GEO is an intergovernmental organization, the term 'GEO Member' applies only to governments; others that join GEO are termed 'Participating Organizations'. As stated in the 10-Year Implementation Plan, "Membership in GEO is open to all member States of the United Nations and to the European Commission. GEO welcomes, as Participating Organizations, intergovernmental, international, and regional organizations with a mandate in Earth observation or related activities, subject to approval by GEO Members. GEO may invite other relevant entities to participate in its activities as observers."

GEO was established on a voluntary and legally non-binding basis, with voluntary contributions to support activities. Collaboration with relevant UN Specialised Agencies and 2

3 All GEO-related documents are available through http://www.earthobservations.org/.
Programmes is also understood to be essential to GEO. This in essence means that all Members and Participating Organizations are working on a best-efforts basis, with some Members providing not only expertise and components, but also dollars and seconded staff. There was an early need identified for a permanent home for GEO and its Secretariat, to which the World Meteorological Organization (WMO) responded with office space and other 'housing' arrangements. GEO is currently headquartered at WMO offices in Geneva, Switzerland.

As of this writing, GEO consists of 66 countries (Members) plus the European Commission, with a Participating Organization roster of 43. All of these organizations are contributing via individuals; some have affiliations with Members in various ways - through space agencies, for example - and so one of the challenges here becomes choosing an avenue for contributions. For instance, because NASA participates heavily in the Committee on Earth Observation Satellites (CEOS), but also participates through the United States via USGEO (described in Section 5), a major challenge is identifying which contributions to send through which channels, consistent with agency mission and funding levels.

As shown in Figure 1, GEO consists of a Plenary, an Executive Committee, a Secretariat, and committees and working groups. GEO meets in plenary at least annually at the senior-official level, and periodically at the Ministerial level. GEO makes decisions by consensus of its Members.

The GEO Secretariat was established in Geneva in May 2005, and the first Director, José Achache, assumed leadership in September 2005. The Secretariat serves as the center of international coordination for the worldwide GEOSS effort.

The role of the GEO Executive Committee is to facilitate the decisions of the GEO Plenary and to oversee and to make recommendations on the implementation of those decisions. It consists of representatives of 12 regionally elected GEO Members (* indicates Co-Chairs)

- Africa - Morocco; South Africa *

- Americas - Brazil, Honduras, United States *

- Asia/Oceania - China *, Japan, Thailand

- Commonwealth of Independent States - Russian Federation

- Europe - European Commission*, Germany, Italy. 


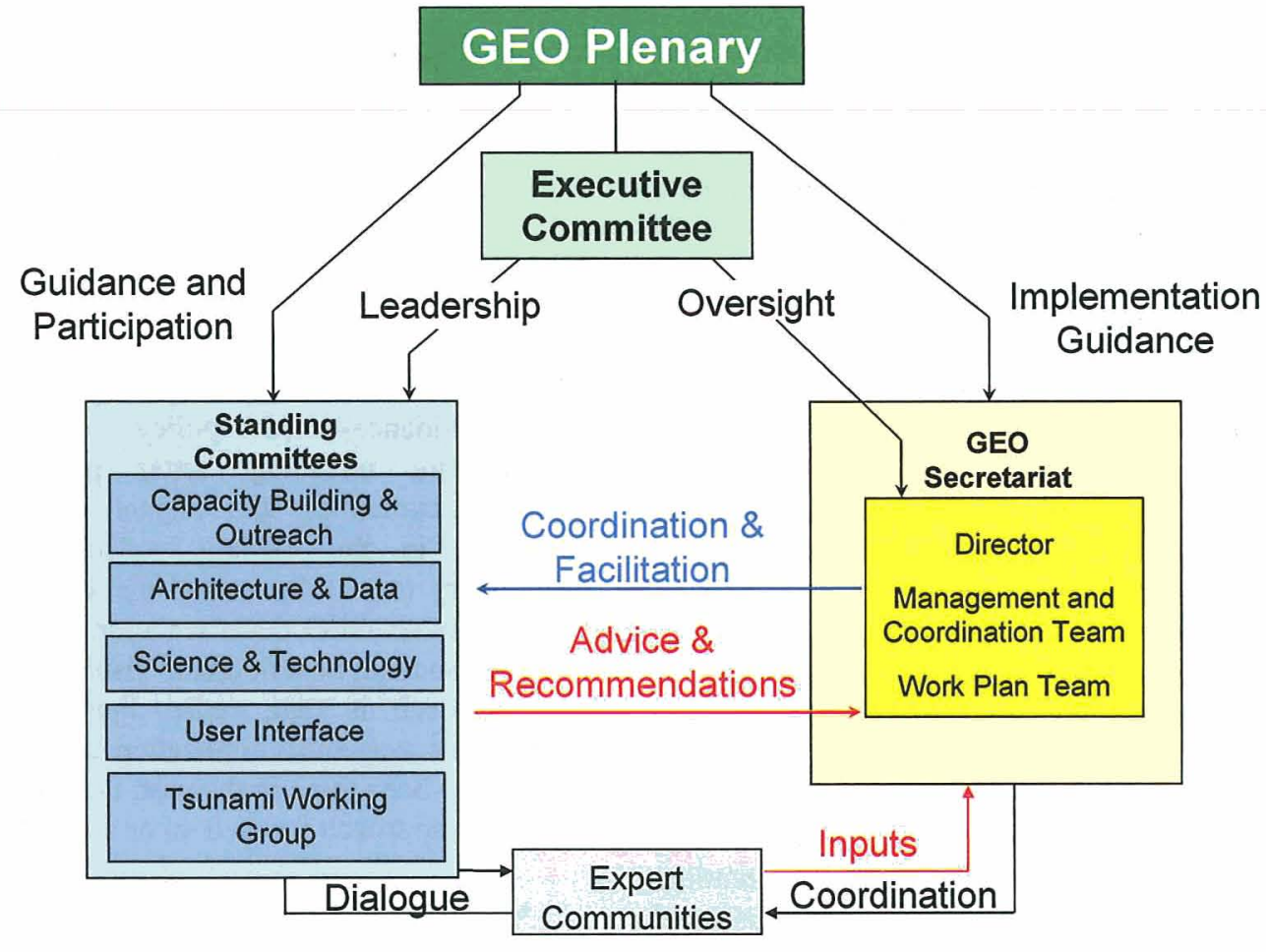

Figure 1. GEO Structure. This diagram highlights the organizational entities present in GEO today, as well as their relationships.

\section{Committees and Working Groups}

Four Committees and one Working Group were carried over from the ad hoc GEO to GEO, and are briefly discussed below.

Capacity Building and Outreach Committee - supports GEO in strengthening the capability of all countries, in particular developing countries, to use Earth observation data and products in a sustainable manner and to contribute observations and systems to GEOSS.

Objectives -

- Facilitate Earth observation capacity building activities among GEO Members, in concert with GEO Participating Organizations.

- Build global capacity to access, retrieve, analyze, include into appropriate models, and interpret relevant data from global data systems.

- Build global capacity to integrate Earth observation data and information with data and information from other sources, improving understanding of problems in order to identify sustainable solutions.

- Develop a coordinated capacity building strategy among GEO members and participating organizations based on the principles articulated in the GEOSS 10-Year Implementation Plan Reference Document.

- Recommend strategies for resource mobilization.

Architecture and Data Committee - supports GEO in all architecture and data management aspects of the design, coordination, and implementation of GEOSS for comprehensive, coordinated, and sustained Earth observations.

\section{Objectives -}

- Enable GEO, based upon user requirements and building on existing systems and initiatives, to define the components of GEOSS, and to converge or harmonize observation methods, and to promote the use of standards and references, intercalibration, and data assimilation.

- Enable GEO to define and update interoperability arrangements to which GEO Members and Participating Organizations agree to adhere, including technical specifications for collecting, processing, storing, and disseminating shared data, metadata and products.

- Enable GEO to facilitate data management, information management, and common services, and will help to promote data sharing principles in support of the GEO Plenary for the full and open sharing and exchange of data and information, recognizing relevant international instruments and national policies and legislation.

Science and Technology Committee - engages the scientific and technological communities in the development, implementation and use of a sustained GEOSS in order to ensure that GEO has access to sound scientific and technological advice. 
Objectives -

- Enable GEO to make decisions on best available and sound scientific and technological advice, through the solicitation of input from a broad, trans-disciplinary scientific and technological community

- Ensure scientific and technological integrity and soundness of GEO Annual Work Plans.

- Monitor and review output and deliverables of GEO Annual Work Plans.

- In collaboration with GEO Members and participating organizations, and through transparent processes, identify individual experts and groups to participate in GEO working groups.

- Facilitate linkages and partnership with major relevant international research programs as well as organizations willing to contribute to GEO activities.

User Interface Committee - engages users in the nine societal benefit areas in the development, implementation, and use of a sustained GEOSS that provides the data and information required by user groups on national, regional and global scales. The User Interface Committee has a specific goal to address cross-cutting issues by coordinating user communities of practice, ensuring continuity and avoiding duplication.

Objectives -

- Enable GEO to address the needs and concerns of a broad range of user communities in developing and developed countries, across issues and transdisciplinary needs, with a particular focus on fostering new or less organized communities.

- Enable GEO, in the implementation of GEOSS, to engage a continuum of users, from producers to the final beneficiaries of the data and information

- Facilitate linkages and partnerships between established communities of practice and new groups or organizations interested in collaborating.

Working Group on Tsunami Activities - supports the coordinating activities of the UNESCO Intergovernmental Oceanographic Commission (IOC) and other national, regional, and international initiatives to realize effective warning and mitigation systems for natural hazards, as an integral part of a multi-hazard approach supported by GEOSS.

Objectives -

- Facilitate the coordination of international programs on disaster prevention and mitigation.

- Develop a multi-hazard multi-purpose approach to early warning and crisis management.

- Promote the interoperability and compatibility of warning and mitigation systems through the development of standards and protocols.

- Facilitate the development of high-level stakeholders' commitments to warning and mitigation systems.

- Support and help ensure durability of capacity building related to infrastructure and training \& education.

\section{Societal Benefit Areas}

Recall that one of the major drivers for GEOSS was that citizens are increasingly requiring their governments to make evidence-based policy decisions about the environment, including better predictions of natural disasters, epidemics, the impact of energy choices, or variations in the climate. The international, multidisciplinary team that created the 10 -Year implementation plan and other GEO documentation framed the question in terms of 'societal benefit areas,' listed below. The power of this approach is that, rather than building observation systems for a specific application and adapting it to other uses as has been done in the past, the emphasis is now on an integrated approach focused on or across these areas:

- Reducing loss of life and property from natural and human-induced disasters.

- Understanding environmental factors affecting human health and well-being.

- Improving management of energy resources.

- Understanding, assessing, predicting, mitigating, and adapting to climate variability and change.

- Improving water resource management through better understanding of the water cycle.

- Improving weather information, forecasting and warning.

- Improving the management and protection of terrestrial, coastal and marine ecosystems.

- Supporting sustainable agriculture and combating desertification.

- Understanding, monitoring and conserving biodiversity.

\section{USGEO}

Every GEO member has, at some level, created an internal organization to help with the GEO effort. Here in this country, the United States Group on Earth Observations is the US response. USGEO's goals are shown here

- "...to develop and begin implementation of the U.S. framework and 10 year plan for an integrated, comprehensive Earth observation system [the Integrated Earth Observation System (IEOS)] to answer environmental and societal needs, including a U.S. assessment of current observational capabilities, evaluation of requirements to sustain and evolve these capabilities considering both remote and in situ instruments, assessment of how 


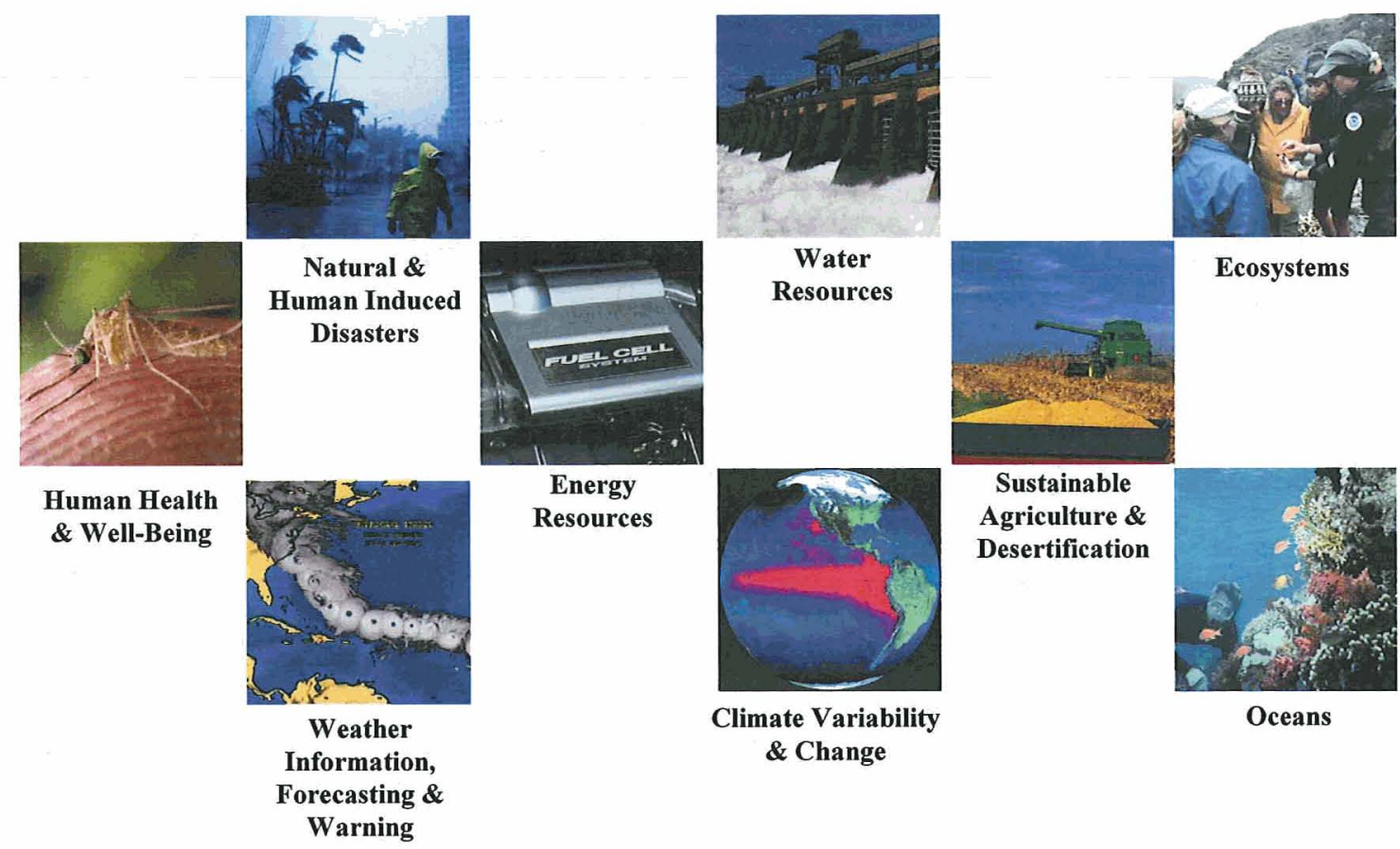

Figure 2. The nine Societal Benefit Areas to be addressed initially by GEOSS. A coordinated Earth observation system is an excellent example of science serving society.

to integrate current observational capabilities across scales, and evaluation and addressing of data gaps"

- "...to formulate the U.S. position and input to the international ad hoc Group of Earth Observations (GEO) as formed at the Earth Observation Summit on July $31,2003 . "$

Figure 3 below shows the committees of the National Science and Technology Council (NSTC), which falls under the Office of Science and Technology Policy (OSTP). The main role of the OSTP is to advise the President and provide science and technology analysis and judgment with respect to major policies, plans, programs, and budgets. OSTP also leads the interagency effort to develop sound science and technology policies and budgets, sets forth (along with the Office of Management and Budget) the research and development priorities to guide the agencies when developing their budgets, and co-chairs the NSTC. NSTC itself is a Cabinet-level council of advisers to the President on science and technology, and is the principal means to both coordinate science and technology matters within the Federal research and development enterprise, and to establish clear national goals for Federal science and technology investments. NSTC consists of four committees: the Committees on Science, Technology, Environment and Natural Resources, and the National \& Homeland Security. USGEO is one of the standing subcommittees under the Environment and Natural Resources Committee (CENR), which also contains the other subcommittees on global change research, disaster reduction (which tracks to the
GEO Tsunami Working Group), Air Quality, and so on.

USGEO's location within CENR is important because it enables USGEO to think about the observation system aspects behind the science being proposed through the Other committees. As noted earlier, a major role of USGEO is " ...to develop and begin implementation of the U.S. framework and 10 year plan for an integrated, comprehensive Earth observation system to answer environmental and societal needs," and so the position of USGEO within the CENR also affords prime opportunities for joint meetings and collaborations.

Figure 4 shows the structure of USGEO. Note the alignment with GEO, as well as the near term opportunity task forces. These task forces are short-term, highly focused teams that take one single, well-defined subject and devise a plan of attack as it were. The current co-chairs of USGEO are NASA, the National Oceanic and Atmospheric Administration (NOAA), and OSTP. Each of these working groups has a similar set of goals and objectives to those of GEO, but these are focused more towards integrating national efforts for our own uses and in support of GEO.

The USGEO strategic plan (available through the website) shows the U.S. versions of the nine societal benefit areas, listed below. They track very well with GEO areas; any gaps would be addressed through the USGEO planning process. 


\section{National Science \\ and Technology Council}
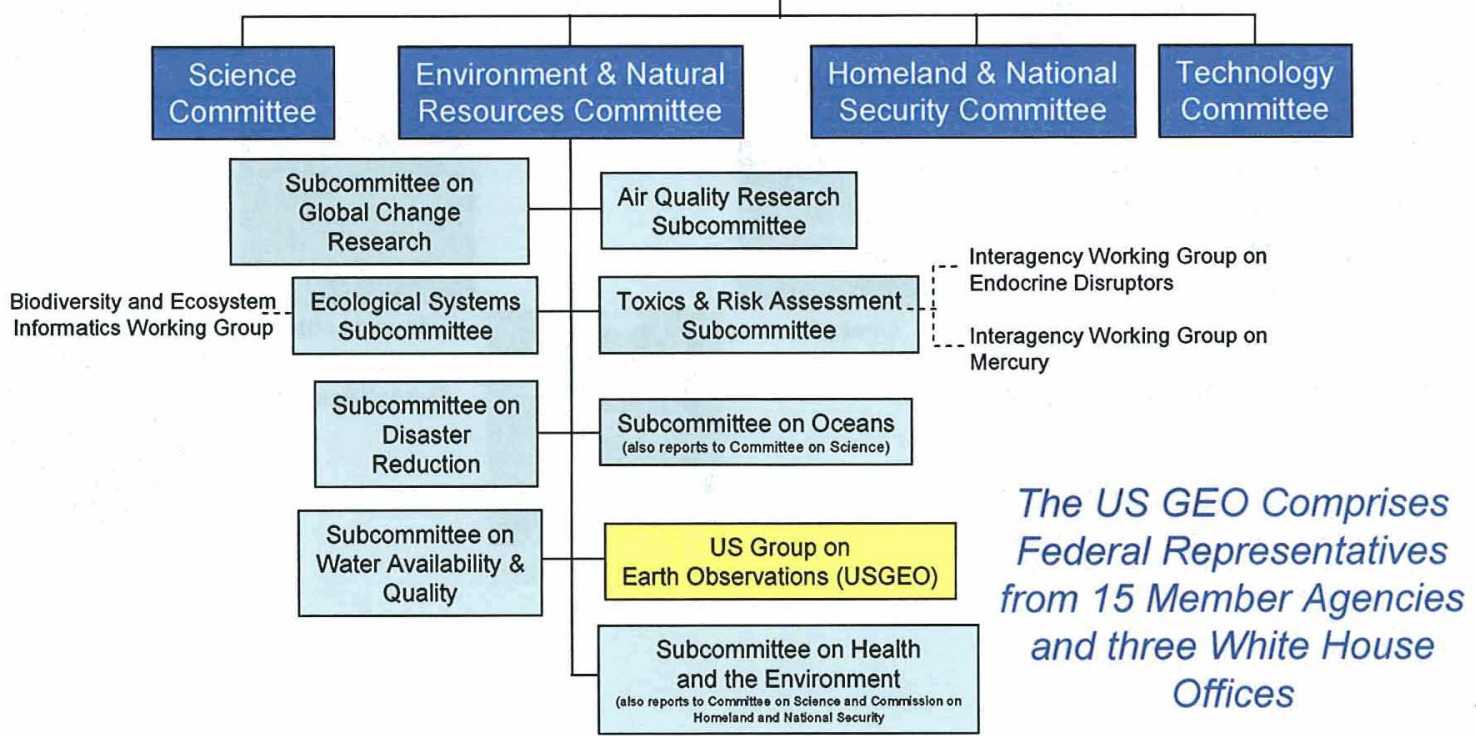

Figure 3. Organization of the National Science and Technology Council. The placement of USGEO within the CENR affords many opportunities for joint participation and collaboration.

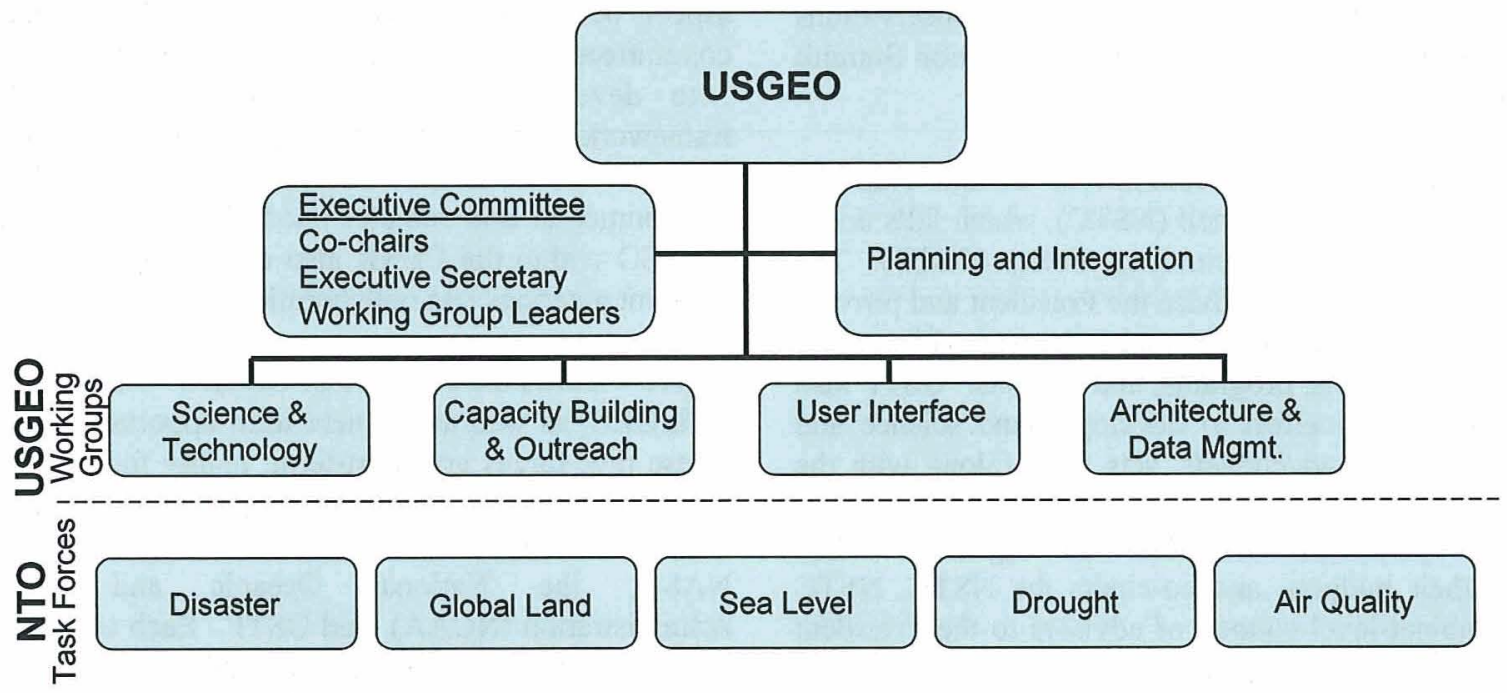

Figure 4. The organization of USGEO. 
- Improve Weather Forecasting

- Reduce Loss of Life and Property from Disasters

- Protect and Monitor our Ocean Resources

- Understand, Assess, Predict, Mitigate and Adapt to Climate Variability and Change

- Support Sustainable Agriculture and Combat Land Degradation

- Understand the Effect of Environmental Factors on Human Health \& Well Being

- Develop the Capacity to Make Ecological Forecasts

- Protect and Monitor Water Resources

- Monitor and Manage Energy Resources

The emphasis on the U.S. plan to realize the IEOS is on integration, as opposed to coordination at the GEO level, largely because it is easier to harmonize within one government, but also because, as a policy organization with ties into science and technology, OSTP and NSTC provide a very fertile ground for exchange of ideas, and resources where allowed. There are four areas of integration that USGEO addresses at some level - Planning, Policy, and Management; Societal Benefits; Scientific; and Technical.

\section{Planning, Policy and Management Integration}

The reader is no doubt familiar, at some level, with the challenges surrounding the Federal budget process. In order to responsibly spend the taxpayer's money, every agency must have some sort of strategic plan that aligns its goals, management, funding, personnel, and all other processes in order to fulfill its mission. Add these differing approaches and processes to the overarching efforts such as the Ocean.US plans, Climate Change Science Program plans, and so on, and one can begin to see the degree of complexity just within the U.S.

However, in writing inter/cross agency plans such as these, agencies have both the opportunity and the challenge of highlighting and integrating their most effective policies, best processes, and most responsive approaches together to achieve the goals at hand. Harmonizing these, across agencies needs to be done in order to leverage both the important base of work already done, as well as everdwindling resources.

\section{Societal Benefits}

The integration challenge behind the societal benefits is also complicated in that the science results that could be critical in one area may not apply to another, while some science can be applied to many societal benefit areas. Figure 5 represents the flow of data and information from sensors of all kinds, through decision support processes, to the decision-makers, and then the feedback into the system. This same flow of data and information is valid for any societal benefit area - the particulars underneath these boxes may be slightly different depending upon whether we are discussing satellite-based imagery, health and human welfare statistics, or in-situ data. But the goal is to enable the wise decision-making in each societal benefit area.

\section{Science}

For many years, NASA's Earth science program, as one example, has been addressing this issue through its research plans, focused on six Science Focus Areas. Discovering how the Earth's systems function - what are their forces and drivers - is a fundamental goal of NASA Earth Science. As such, NASA modelers and researchers have been doing some form of integration for a very long time. But now, USGEO member agencies are working together in areas where the might be in some completely different part of the system. Through USGEO, there is a unique opportunity to identify where and how to leverage the work done to date.

\section{Technical}

Technology has allowed us to obtain data from the sub-1 meter range all the way to the $10,000 \mathrm{~km}$ range, and it is known that integration at such scales can be critical to human well-being. Weather forecasting is a prime example. The weather satellites that NASA's Goddard Space Flight Center builds for NOAA to operate, when combined with radar, airplane, and rain gauge data, as well as sophisticated computer modeling, produce the daily weather forecasts that tell the public whether they need an umbrella or a coat today.

The task for USGEO is to learn from successes like this and replicate those where possible, and to take advantage of the perspectives in each of these vantage points, along with their unique capabilities, and apply them to areas that we might not have thought applicable before. 


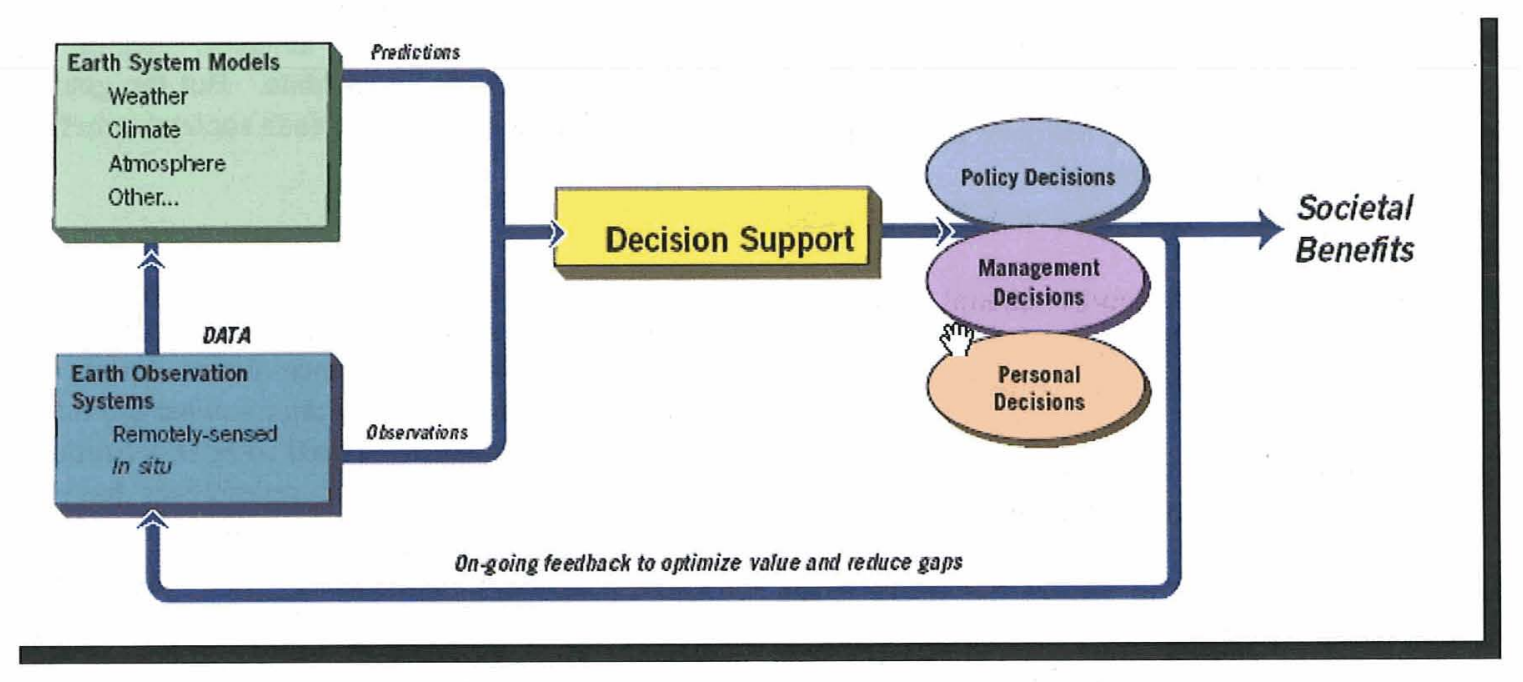

Figure 5. Flow of data and information from sensors to decision-makers. This diagram appears in many forms throughout GEO and USGEO documentation.

\section{OPPORTUNiTIES AND CHALLENGES}

The complexities hinted at in the previous pages illustrate some of the many political, organizational, and technical challenges evident with an effort of the scale of GEOSS. This section highlights only a few of the opportunities and challenges faced in trying to implement GEOSS and IEOS.

\section{Best-Efforts Approach}

One of the most daunting challenges facing GEO, and yet one which all Members and Participating Organizations face willingly, is that GEO is a best-efforts activity. As mentioned earlier, this means that Members and Participating Organizations do what they can with what they have. This also means, however, that as policy organizations, there is no money or authority for GEO or USGEO proper to write requests for proposals or otherwise directly fund or contract for work. This, in turn, means that all work is done by the Members or Participating Organizations themselves, as consistent with their own missions, national/agency priorities, procurement authority, and budgets. It is stressed within GEO that any Member or Participating Organization which volunteers to lead a task bring the appropriate resources along. While on the surface this seems to present quite a challenge to all participating, this also presents the opportunity to critically assess the importance of any specific activity, as well as its priority, and its actual constituency.

\section{Work Plans}

The way GEOSS is to be realized is through completion of a series of tasks pulled from the 10-Year Implementation Plan and other associated documentation. These tasks are collectively referred to as the GEO Work Plan Tasks, and have hundreds of people assigned to them from all over the world. All tasks have a point of contact for reporting purposes, one or more leads (people from Members or Participating Organizations with the time and resources to shepherd the work) and then as many contributors as want to volunteer. Most work is done electronically; some is done through face-to-face meeting, although, this can put a strain on nations with little or no travel funding.

Besides the challenge of meeting to discuss work, there is the added challenge of the number of tasks that exist. The first work plan [6] contained 96 tasks. Over its year-long schedule, it became clear that some tasks were not necessary, some could be combined, and some should be continued. This critical look led to the second work plan having a more integrated approach. It became clear about mid way through the first work plan that some tasks were linked and could neither be completed nor addressed independently of others. For example, one task asks for the development of a clearinghouse for GEO contributions, while a separate one asks for an inventory of those contributions. Still another asks for a portal to display those contributions and/or to provide some of the services available. While working through these tasks, it became very clear very quickly that all three groups might define the same words in three different ways, thereby creating three simultaneous and incompatible solutions. Those three tasks are now being combined and coordinated to produce a more coherent solution.

It is still too early in the process to clearly identify successful approaches to these challenges, partly because of 
the deliberate, international nature of the efforts, and partly because it has been less than 12 months (as of this writing) since GEO formally began.

\section{Architecture and Data Management}

The USGEO has developed the concept of a near term opportunity (NTO). These are identified in the strategic plan as integrated observing system efforts that could be addressed within two years, using existing resources for high impact outcome. There were six identified initially: Data Management, Improved Observations for Disaster Warnings, Global Land Observation System, National Integrated Drought Information System, and Air Quality Assessment and Forecast System. Each of these has its own scientific challenges, but each also has integration and data management challenges. Because there is currently no comprehensive and integrated strategy for communicating existing data, data management is highlighted as both an overarching need, and the necessary first near-term action for this integrated system.

Clear plans have been developed for these opportunities, which are relevant to national priorities, agency missions, and customer needs. The identified observation needs are high-priority and multi-year in their goals, with tangible results easily identified. These potential outcomes cut across all societal benefit areas identified in this strategy. But they also present their own sets of challenges.

IEOS - The focus of the USGEO Architecture and Data Management Working Group (ADM) is to identify the concepts, principles, tenets, ideas, best practices, or whatever you choose to call them, that would make the IEOS a reality. Because the IEOS is the U.S. contribution to GEOSS, there has to be coordination up and down the line between GEOSS and IEOS. Data management is a necessary first step, however, in achieving the synergistic benefits from the IEOS, and in developing data management systems that are well-linked and support the full information cycle from observation acquisition to information delivery.

At a minimum, the IEOS must address these urgent needs by focusing on specific data management solutions:

- Enable increased interoperability across existing data management systems - by encouraging the agencies and entities involved in Earth observations to identify where their systems can currently contribute to a larger system with a minimum of fuss, and encourage them to offer that system. This is not equivalent, necessarily, to 'plug and play,' but rather, the first efforts in each of the near-term opportunities were around identifying within agencies existing systems which could, with some work on the interfaces, for example, be linked together for a specific purpose.
- Identify and address integration gaps in data management systems - when looking to integrate or link two things, let alone many, the first thing one tries to do is see how they fit together or see how they communicate (or don't, as the case may be). Finding those gaps, identifying them as in need of filling is something the ADM hopes to facilitate. For instance, when interviewed about data and architecture needs, each of the NTO teams said that having some kind of dedicated portal would greatly enhance their chances of success. The ADM is currently working with two of the NTO teams to realize that need.

- Utilize community standards for data and metadata - in the spirit of keeping the minimum of things the same so that everything else can be different, working on the interfaces between systems or parts of systems by utilizing community standards where available is seen as the ideal approach. The ADM is not a standards body, and does not create or adopt standards, but can encourage their use where practicable.

- Enable integrated measurements, data, products, and predictive models - the near term opportunities all identified an integrated approach to satisfying the needs of that part. For instance, the Global Land Observation System would like to have, high resolution digital topographic data including digital maps as one of its outputs. The data sets, tools, services, and models required to produce those maps should not be predicated on any of the issues listed above.

- Examine the need for future data management requirements - as with any system, there will be pieces and parts not foreseen when working on the bullets above. The ADM will be constantly looking at what's out there, what the state of the art is with respect to data management at all levels, and doing whatever possible to infuse the best of those efforts into the national picture.

System of Systems Architecture - Perhaps one of the most intriguing challenges that has presented itself to date is that of how to build a reference architecture for a system of systems which is not, actually, one, single, physical computer system that can be enclosed in a single building. Anyone familiar with the reference architecture process knows that one of the first steps to producing such a document is to gather the requirements from the users, then proceed from there. Reference architectures are a critical piece, allowing system developers to check against reality in all phases of a project. The GEOSS and IEOS architecture describes how components fit together to produce an overall 
system of systems capable of providing data and information that will better satisfy requirements than the individual components or systems of which it is composed. Both will build step-by-step on current cooperation efforts among existing observing and processing systems within their mandates, while encouraging and accommodating new components. Initially, all contributions will be combinations of systems and services established for some other reason, with no funding having been set aside for serendipity, so the more accommodating, the greater the chance of success.

In the case of both GEOSS and the IEOS, what is being discussed is the ability to enable existing systems through a service-oriented architecture approach. This approach affords the highest degree of flexibility in that it allows providers of data, services, and other critical components to make their contributions without having to significantly modify those contributions (in most cases). Having said that, however, it is still being debated how best to describe, and then diagram, a reference architecture for a system of systems. As a system of systems, the success of GEOSS and IEOS will depend a great deal on how well the contributed systems achieve interoperability.

\section{Closing Remarks}

The vision for GEOSS and IEOS is to realize a future wherein decisions and actions for the benefit of humankind are informed via coordinated, comprehensive and sustained Earth observations and information. This vision will be achievable through careful planning, critical thinking, and wise leveraging of existing and planned resources and efforts worldwide. The challenges and opportunities identified in this paper will be overcome in time, and new ones will replace them. But it is equally clear that the goal of enabling evidence-based decisions cannot realistically be met without carefully calibrated, validated science and modeling results. GEO and USGEO, as well as efforts from other nations, will continue to provide the necessary forums for this critical work.

\section{REFERENCES}

[1] Global Earth Observation System of Systems 10-Year Implementation Plan,

http://www.earthobservations.org/docs/10-Year\%20

Implementation\%20Plan.pdf

[2] Battrick, Bruce (ed.), Global Earth Observation System of Systems 10-Year Reference Document, February 2005.

[3] United Nations Environment Programme, Global Progamme of Action for the Protection of the Environment from

Land-Based

Activities, http://www.gpa.unep.org/bin/php/programs/ padh/index.php.

[4] Maxx Dilley, Robert S. Chen, Uwe Deichmann, Arthur L. Lerner-Lam, Margaret Arnold, "Natural Disaster Hotspots: A Global Risk Analysis," World Bank Publications, 2005.

[5] Godwin O.P Obasi, Secretary General of the WMO, March 20, 2003 press release in honor of World Meteorological Day.

[6] GEO Work Plan 2006, Version 4. March 30, 2006.

\section{BIOGRAPHY}

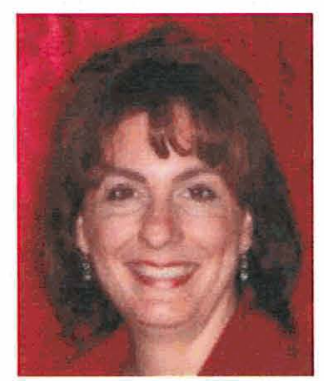

Kathy Fontaine began her policy career at NASA in the Mission to Planet Earth Program Office at the Goddard Space Flight Center in 1993. Since 2003, she has been working on general policy issues of interest to NASA and its Earth science data community. She now manages a set of community-based working groups examine issues of interest to the Earth science community. She is a member of the Office of Science and Technology Policy (OSTP) Committee on the Environment and Natural Resources (CENR) United States Global Earth Observation (USGEO) Subcommittee, serving as Co-Chair of the Planning and Integration (PnI) Team, and as Vice Chair of the Architecture and Data Management Working Group. At the international level, she is the NASA representative to the CEOS Working Group on Information Systems and Services (WGISS). In both of these groups, her role is to provide policy and technical expertise and guidance on data management, data policy, and data systems architecture issues from the NASA perspective.

She received a BS in Physics (Astrophysics) from the New Mexico Institute of Mining and Technology in 1984, and an MA in Science, Technology, and Public Policy from the Elliott School of International Affairs at The George Washington University, Washington, DC, in 2002. Ms. Fontaine is a member of AIAA, AGU and Women in Aerospace, and has been listed in Who's Who in America since 2004. She has authored or co-authored over a dozen papers and articles on various aspects of Earth science policy. 